\title{
CALCULATED EFFECTS OF NITRIC OXIDE FLOW CONTAMINATION ON SCRAMJET PERFORMANCE
}

\author{
Karen E. Fischer* and Kenneth E. Rock* \\ NASA Langley Research Center, Hampton, VA 23681
}

\begin{abstract}
$\underline{\text { Abstract }}$
The level of nitric oxide contamination in the test gas of the NASA Langley Research Center Arc-Heated Scramjet Test Facility and the effect of the contamination on scramjet test engine performance were investigated analytically. The study was conducted for standard facility conditions corresponding to Mach 6, 7, and 8 flight simulations. The analytically determined levels of nitric oxide produced in the facility are compared with experimentally measured levels. Results of the analysis indicate that nitric oxide levels range from one to three mole percent, which corroborates the measured levels. A three-stream combustor code with finite rate chemistry was used to investigate how nitric oxide affects scramjet performance in terms of combustor pressure rise, heat release, and thrust performance. Results indicate minimal effects on engine performance for the test conditions of this investigation.
\end{abstract}

\section{Introduction}

The NASA Langley Research Center Arc-Heated Scramjet Test Facility (AHSTF) has been used as a hypersonic airbreathing propulsion test facility for nearly twenty years. As with other types of propulsion facilities (e.g., combustion-heated, shock-heated, etc.), a vitiated test gas is a direct consequence of heating the air to achieve the necessary stagnation enthalpy for flight Mach number simulation. In the AHSTF, a portion of the incoming air is heated by an electric arc to temperatures near $4400 \mathrm{~K}$. At this temperature, air becomes partially dissociated and significant levels of atomic oxygen and nitrogen oxides $\left(\mathrm{NO}_{\mathrm{X}}\right)$ exist. Further processing of the air (by mixing with unheated air and by expansion) allows the atomic oxygen to recombine upstream of the test section; however, small amounts of $\mathrm{NO}_{\mathrm{X}}$, primarily in the form of nitric oxide $(\mathrm{NO})$, remain in the test gas.

\footnotetext{
${ }^{*}$ Aerospace Research Engineer, Hypersonic Airbreathing Propulsion Branch, Member AIAA.

Copyright (C) 1995 by the American Institute of Aeronautics and Astronautics, Inc. No copyright is asserted in the United States under Title 17, U.S. Code. The U.S. Government has a royalty-free license to exercise all rights under the copyright claimed herein for government purposes. All other rights are reserved by the copyright owner.
}

In addition to nitric oxide, copper contaminant is also released at the arc attachment points inside the heater. Reference 1 addresses the various types of flow contamination in arc-heated facilities including both NO and copper contamination. For the facility studied in reference 1 (the AEDC HEAT-H1 arc heater), the maximum copper contamination level, approximately $90 \mathrm{ppm}$ mole fraction of copper vapor, was predicted to slightly reduce reaction times in hydrogen/air combustion tests. In the present study, copper flow contamination was not considered and only the levels and effects of $\mathrm{NO}$ contamination were examined.

$\mathrm{NO}_{\mathrm{X}}\left(\mathrm{NO}\right.$ and $\left.\mathrm{NO}_{2}\right)$ contamination is a concern in scramjet engine testing because any deviation in the composition of the test gas from atmospheric air may affect combustion and engine thrust performance. Therefore, for the results of AHSTF engine tests to be interpreted in terms of true flight, it is necessary to account for the effects of NO in the test gas. One effect of nitric oxide is to reduce the amount of oxygen available for reaction with the fuel. Conversely, studies have shown that, under certain conditions, NO enhances combustion heat release. ${ }^{2,3}$ The ultimate effect of NO contamination in the AHSTF must be investigated for the NO levels and test conditions specific to the facility.

This paper presents an analysis in two parts. In the first part, a one-dimensional finite rate chemistry code was used to analyze the flow through each component of the AHSTF over a range of operating conditions corresponding to Mach 6, 7, and 8 flight simulations. A six-reaction mechanism for dissociated air was employed in the code. The air composition was computed at discrete stations up to the test section entrance, where calculated NO levels were compared with experimentally measured levels. The second part of the analysis continues the modeling of the air flow through a representative test engine flow path. In this analysis, a one-dimensional, quasi-three-stream code with finiterate chemistry was used for the engine combustor and nozzle flow segments. A 68-reaction air-hydrogensilane mechanism was used to model the combustion process. This second part of the analysis focused on the Mach 8 flight simulation for injected fuel equivalence ratios of $0.5,1.0$, and 1.5. An investigation of the effect of $\mathrm{NO}$ was made by comparing calculated engine 
performance for NO-contaminated air with that for nondissociated atmospheric air.

\section{Symbols}

A2 engine combustor entrance area

$\mathrm{A}_{\mathrm{e}} \quad$ engine nozzle exit area

F sum of the pressure and skin friction forces on the engine combustor and nozzle

$\mathrm{h}_{\mathrm{t}, \infty} \quad$ flight stagnation enthalpy and facility stagnation enthalpy

$\dot{\mathrm{m}}_{\mathrm{a}}$ mass flow rate of air entering the engine

$\dot{\mathrm{m}}_{\mathrm{f}}$ mass flow rate of fuel injected into the engine

$\mathrm{M}_{\infty} \quad$ flight Mach number

M1 Mach number at the facility nozzle exit/engine entrance plane

$\mathrm{NO}_{\mathrm{X}} \quad$ nitrogen oxides

NO nitric oxide

$\mathrm{p} \quad$ static pressure

$\mathrm{p}_{\mathrm{t}, 1}$ stagnation pressure behind vehicle bow shock, also facility stagnation pressure

$\mathrm{P}_{\mathrm{arc}}$ arc power

$\mathrm{p}_{1} \quad$ static pressure at the facility nozzle exit/engine entrance plane

$\mathrm{p}_{2}$ static pressure at the engine inlet exit/combustor entrance plane

pe static pressure at the engine nozzle exit plane

T static temperature

V velocity

$\mathrm{V}_{2}$ velocity at the engine combustor entrance plane

$\mathrm{V}_{\mathrm{e}} \quad$ velocity at the engine nozzle exit plane

$\Delta \mathrm{F} \quad$ change in engine thrust from fuel-off to fuel-on conditions $\emptyset_{\text {tot }}$ total fuel equivalence ratio

$\varnothing_{\mathrm{H} 2}$ equivalence ratio of hydrogen

$\eta_{\mathrm{m}} \quad$ fuel-air mixing fraction

\section{Facility Description}

The purpose of the NASA Langley AHSTF is to generate high energy flows for testing airframeintegrated scramjet engine modules for hypersonic vehicles. An example of such a vehicle in flight is depicted in figure 1(a) with the corresponding ground facility simulation for the engine shown in figure 1(b). The goal in the AHSTF is to deliver a test flow with the same conditions as the air entering the engine shown in figure $1(\mathrm{a})$ over a flight Mach number $\left(\mathrm{M}_{\infty}\right)$ range from 4.7 to 8 . Vehicle bow shock precompression is simulated by expanding the test gas to a Mach number, $M_{1}$, which is less than the flight Mach number and corresponds to the conditions ahead of the engine entrance.

Figure 2 shows the test capability of the AHSTF in terms of flight altitude and Mach number. Tests can be conducted at stagnation enthalpies and pressures corresponding to the flight Mach number range and altitudes indicated by the envelope. Also shown in figure 2 , on the lower axis, is the free stream stagnation temperature range which corresponds to the test Mach number range. These temperatures, ranging from approximately $1100 \mathrm{~K}$ to $2800 \mathrm{~K}$, must be duplicated in the stagnation region upstream of the facility nozzle expansion.

Detailed descriptions of the AHSTF are given in references 4 and 5; therefore, only the steps involved in processing the facility air are explained in this paper. Figure 3 is a schematic of the three primary components upstream of the facility test section: the arc heater, the plenum chamber (including the plenum injector rings) and the nozzle. The arc heater is a cylindrical vessel comprised of an upstream and downstream electrode. The air entering the heater, referred to as "main air", is heated by an electric arc which is established between the upstream and downstream electrodes. Except for the arc attachment points, the arc is confined to the centerline of the heater by the vortex flow of the main air which is injected with a swirl component. According to reference 1, in a typical arc heater, only a small fraction of the mass flow (less than 5 percent) is actually resident in the arc or "discharge" and is heated directly by the arc. The larger fraction of the main air is heated relatively slowly by radiation and conduction. The resulting air exits the heater at a 
stagnation temperature of approximately $4400 \mathrm{~K}$ in a highly dissociated state.

This dissociated main air then enters the plenum chamber where unheated, or "bypass air", is injected through the plenum injector rings and is mixed with the main air. The bypass air is added in an amount necessary to achieve a mixture stagnation enthalpy, $\mathrm{h}_{\mathrm{t}, \infty}$, corresponding to the desired altitude and flight Mach number simulation. Typical values of the main and bypass air flows are included in table 1 which lists nominal facility operating parameters for standard Mach 6,7 , and 8 flight simulations. Although heater conditions (in terms of arc power and main air flow) are the same for the three simulations, lower simulated flight stagnation enthalpies are achieved by increasing the mass flow rate of the bypass air. The bypass air is injected radially through the plenum injector rings in an attempt to break up the swirling motion of the main air exiting the heater and to enhance mixing of the two air streams. This method of heating only a portion of the total air to elevated temperatures and then mixing it with cooler air to achieve the desired test conditions is necessary because the heater cannot operate in a stable mode while processing the full facility air flow. ${ }^{4}$ The resulting air mixture exiting the plenum is expanded through a converging/diverging supersonic nozzle and enters the test section. For the $M_{\infty}=6,7$, and 8 flight simulations, the nozzle expands the flow to an aerodynamic Mach number of $\mathrm{M}_{1}=6$, thus simulating varying degrees of forebody precompression.

The electrodes, plenum injector rings, plenumchamber wall, and nozzle throat are made of copper and are water cooled. During a test, the heat transferred from the walls of each of these components is calculated from an energy balance on the cooling water to each component. For a series of recent Mach 6, 7, and 8 tests, these component heat losses were computed as a percentage of arc power. Although higher operating pressures yielded slightly higher percentage heat losses, this analysis will use values averaged over the Mach 6 to 8 range. These average heat losses are listed in table 2 .

\section{$\underline{\text { NO }} \underline{x}$ Concentration in the Facility}

\section{$\underline{\text { Analysis }}$}

To determine the $\mathrm{NO}_{\mathrm{X}}$ concentration in the facility, a finite rate kinetics code was used to model the flow through each of the major components (heater, plenum, and nozzle) upstream of the facility test section. The program used was that described in reference 6 for solving problems of chemically reacting gas mixtures. The reaction scheme and rate constants used to describe the air dissociation and recombination ${ }^{2}$ are given in table 3. The code assumes that the flow is one-dimensional, adiabatic, and inviscid. Because of the adiabatic assumption, heat transfer must be modeled externally to the code. The chemical composition and flow properties along the flow path were computed for a specified initial starting composition, pressure, temperature, and velocity. The flow through each facility component was analyzed individually by specifying either a pressure distribution or an area distribution for the flow process. Area discontinuities and mass addition between components were accounted for external to the code.

The analysis was carried out by performing an energy balance on the individual components. First, the stagnation enthalpy of the air at the heater exit was calculated using the incoming main air flow rate and arc power from table 1, taking into account the heat loss to the electrodes (table 2). The code was then used to model the chemically reacting flow through the heater at a stagnation enthalpy matching the exit enthalpy computed above, starting with an initial composition of the atmospheric incoming air. This procedure, in effect, models the heat transfer separately from the chemical reactions by enforcing instantaneous heat addition at a frozen composition of the nondissociated atmospheric air, then allowing reactions to take place adiabatically as the air flows through the heater.

A similar procedure was followed for the plenum chamber and nozzle. For the plenum, the starting composition was computed from an instantaneous and chemically frozen mixing of the dissociated main air and the nondissociated atmospheric bypass air. Reactions were then allowed to take place at a constant enthalpy equal to the plenum exit stagnation enthalpy, which was calculated from an energy balance of the plenum flow process. For the nozzle, the area distribution of the contoured converging section was assigned and the stagnation enthalpy was set equal to the enthalpy required to choke the nozzle for the prescribed stagnation pressure, mass flow and throat area. In the analysis of the diverging nozzle section, no further heat was removed in an attempt to model only the core flow to the nozzle exit. The gas was allowed to react as it expanded along an assigned area distribution to the $M_{1}=6$ nozzle exit condition. In this way, the test gas composition was computed throughout each component up to the facility test section entrance.

\section{Results and Discussion}

The amount of dissociation which takes place in the heater is presented in figure 4 by specie concen- 
tration traces for the Mach 7 flight simulation, which are representative of all three flight Mach number simulations. The results for the flow through the heater are nearly the same for all three Mach number simulations because of the identical arc power and heater air flow rates; however, there is a small pressure effect. In all cases, equilibrium is reached within approximately $2 \times 10^{-2}$ milliseconds which is small relative to the heater residence times of 6 to 10 milliseconds. The heater exit state for each flight Mach number simulation is given in table 4. The $\mathrm{NO}_{\mathrm{X}}$ species, ranging from 8 to 9 mole percent, are primarily composed of $\mathrm{NO}$, with trace amounts of $\mathrm{NO}_{2}$. A high level (approximately 15 mole percent) of atomic oxygen also exits the heater.

Results for the flow through the plenum and nozzle indicate that both the atomic oxygen and nitric oxide are significantly reduced. In all cases, the atomic oxygen recombines and is reduced to less than 0.01 mole percent by the time the flow reaches the test section; however, notable levels of NO remain. Calculated NO concentrations throughout the heater, plenum and nozzle are shown in figure 5 for the three Mach number simulations. The trends are explained as follows. In all of the cases, the NO in the flow exiting the heater is initially diluted in the plenum by the mixing with the bypass air as shown at the start of the plenum. The dilution is greatest for the lowest enthalpy $\left(\mathrm{M}_{\infty}=6\right)$ simulation which requires the most bypass air. The instantaneous temperature drop used to model the cooling, places the gas in a nonequilibrium state. As the air flows through the plenum, the dissociated species begin to recombine with an associated temperature increase. However, the level of reactivity is dependent on the extent of initial cooling.

For the Mach 6 enthalpy case, in which the most bypass air is injected in the plenum, the NO is diluted to 2.3 mole percent. Rapid initial recombination of atomic oxygen and nitrogen takes place, after which the composition freezes and the NO remains at the diluted level of 2.3 percent, compared with less than 1 percent had equilibrium occurred. The flow remains essentially frozen throughout the facility nozzle for the Mach 6 enthalpy case. In the Mach 7 enthalpy simulation, the flow is somewhat more reactive due to the higher temperature, but reactions are too slow to reach the equilibrium composition. After dilution to 3.1 percent at the plenum entrance, the NO decreases to 2.2 percent, compared with an equilibrium level of around 1 percent. In the nozzle, some further recombination of atomic oxygen occurs, but the NO level remains nearly constant and the composition freezes near the throat. For the Mach 8 enthalpy condition, less bypass air is injected and the temperature remains high enough such that reaction rates are sufficiently high for the flow to reach chemical equilibrium within the plenum residence time. The amount of NO decreases rapidly from 4.2 mole percent after dilution to an equilibrium level of 3.3 percent. In the nozzle, equilibrium is maintained until just upstream of the throat, and the NO is reduced to 3.1 mole percent. Downstream of the throat, reaction rates decrease and the NO level remains constant. The plenum and nozzle exit states for the Mach 6, 7, and 8 cases are given in table 5 .

\section{Comparison with Data}

Figure 6 compares the calculated NO levels with experimentally measured NO levels at the facility nozzle exit versus the stagnation enthalpy. There are three sources of experimental measurements. The first, represented by the open circles in figure 6 , are gas samples taken during a series of facility operability tests conducted in 1983. ${ }^{5}$ Samples were collected in bottles through a probe placed at the exit of a metering nozzle installed downstream of the plenum. The second source of data (shown as square symbols) is from a series of tests conducted in collaboration with Arnold Engineering Development Center (AEDC) in 1989, specifically to measure NO densities in the AHSTF. 7 These were nonintrusive measurements using a NO resonance absorption technique. The third source of experimental data (shown by triangle symbols) are probe samples taken during a series of tests in 1992 using a mass spectrometry system. A curve is also shown representing calculated NO levels assuming equilibrium is reached in the plenum and frozen flow in the nozzle.

As shown in figure 6, considerable scatter exists in the experimental data at all stagnation enthalpy simulations. However, the finite rate calculated levels and the experimental NO levels show general agreement. Most importantly, both analytical results and experimental measurements indicate that NO concentrations in the AHSTF are between 1.0 and 3.2 mole percent for the flight simulation range from Mach 6 to 8 . The data in figure 6 also show, at the Mach 6 and 7 simulations, that assuming the NO level entering the test section is equal to plenum equilibrium level underpredicts the measured and kinetically calculated NO concentration.

\section{$\underline{N O}_{\underline{x}}$ Effect on Engine Performance}

Even though the NO levels shown in figure 6 are small, the potential effect on scramjet test engine performance was determined. One premise is that $\mathrm{NO}_{\mathrm{X}}$ in the test gas is inert, and effectively reduces combustion heat release by trapping some oxygen that would have 
been available for combustion. However, references 2 and 3 indicate that dissociated species, including NO, can enhance combustion heat release. Both references studied the dissociated test gas in a reflected shock tunnel (the T4 facility at the University of Queensland) simulating combustor inlet conditions for Mach 17 flight. The overall effect of the NO depends on the particular combustor inflow conditions, therefore the effect of NO on test results in the AHSTF was investigated.

For this analytical investigation, the focus was on the Mach 8 simulation, for which the NO concentration was the greatest. The calculated facility nozzle exit flow conditions for the Mach 8 simulation were used to define the inflow for a test engine in the AHSTF. A simple inlet compression was performed, followed by a combustor analysis with fuel equivalence ratios of 0.5 , 1.0, and 1.5. The overall effect of $\mathrm{NO}$ at a Mach 8 simulation was determined by comparing calculated performance using the NO-contaminated air with calculated performance using nondissociated atmospheric air. The nondissociated atmospheric air was defined to be air composed of 78.12 percent $\mathrm{N}_{2}, 20.95$ percent $\mathrm{O}_{2}$, and 0.93 percent Ar (by volume) and will hereafter be referred to only as nondissociated air.

\section{Analysis}

To perform the inlet compression process, a typical subscale model inlet size and contraction ratio for a Mach 8 flight simulation were used. The inlet geometry is shown in figure 7. For this geometry, an inviscid shock train was calculated and used to obtain a pressure distribution for a core streamline. This pressure distribution is shown in figure 8 . The one-dimensional finite rate code of reference 6 was again used with this pressure distribution to model the flow through the inlet. The inflow was defined using the calculated pressure, temperature and velocity at the exit of the facility nozzle for the Mach 8 simulation using both the Mach 8 NO-contaminated air composition (Table 5) and the nondissociated air composition. The code calculated further changes in composition in the inlet and provided combustor entrance flow conditions.

The reacting flow in the combustor was modeled using the one-dimensional, quasi-three-stream combustor code, SCRAM3. ${ }^{2}$ The three streams refer to the unmixed fuel, the unmixed air, and a reaction zone. Separate temperatures were specified for the fuel, the air, and an ignition source. The ignition source provides free radicals and thermal energy necessary to ignite the fuel and air. In this study, the ignition source was formed by allowing 2 percent of the overall fuel-air mixture to react to equilibrium at constant pressure and enthalpy. The fuel stream was assigned a temperature of $300 \mathrm{~K}$ and a pressure and velocity equal to those of the air stream. Mixing of the fuel and air occurred according to a specified mixing schedule to form a near stoichiometric reaction zone.

In the AHSTF, a silane-hydrogen mixture (composed of 20 percent $\mathrm{SiH}_{4}$ and 80 percent $\mathrm{H}_{2}$ by volume) is commonly used as an ignition aid in test engine combustors. Only a small amount is used and remains constant for the duration of the hydrogen fueling. The reaction mechanism used to describe this combustion chemistry includes the 33-reaction hydrogen-air mechanism given in reference 2 which contains thirteen nitrogen and oxygen reactions that allow the NO to take part in the reaction chemistry. Thirty-five additional reactions were recommended by the author of reference 2 to model the silane chemistry. These additional silane reactions and their associated rate constants are given in table 6.

The study was performed for total fuel equivalence ratios of $\emptyset_{\text {tot }}=0.5,1.0$, and 1.5. The contribution of the silane mixture to $\varnothing_{\text {tot }}$ was calculated as a "hydrogen-equivalent" $\varnothing$, based on the hydrogen $\varnothing$ that would be required to release the same amount of heat as the given amount of silane mixture, assuming complete reaction to the gaseous phase (no solid $\mathrm{SiO}_{2}$ formation). For the silane mixture used in the AHSTF, the hydrogen-equivalent $\varnothing$ was computed by multiplying the mixture $\varnothing$ by a factor of 0.944 . In each case, a hydrogen-equivalent $\varnothing$ of 0.15 was used for the silane mixture, with varying amounts of pure hydrogen $\left(\varnothing_{\mathrm{H}_{2}}=0.35,0.85\right.$, and 1.35) making up the remainder of $\emptyset_{\text {tot. }}$ The equivalence ratios were calculated based on the total amount of oxygen in the air, whether in the form of $\mathrm{O}_{2}, \mathrm{O}$, or $\mathrm{NO}_{\mathrm{X}}$.

A typical subscale engine flow path was modeled using a constant-area combustor followed by a nozzle with an expansion ratio of 8 . The area distribution for this configuration is shown in figure 9.

The fuel-air mixing schedule was assigned in the form of a mixing fraction:

$$
\eta_{\mathrm{m}}=1-\mathrm{e}^{-\mathrm{cx}}
$$

where the constant, $\mathrm{c}$ was specified based on a mixing recipe $^{8}$ for perpendicular injection by matching the mixing fraction at the exit of the constant-area combustor. This resulted in the mixing curves shown in figure 10 for $\varnothing=0.5,1.0$, and 1.5 . For $\varnothing$ less than or equal to one, the mixing fraction was defined as the fraction of total fuel that has mixed and been allowed to react with a stoichiometric amount of air. For $\varnothing$ greater than one, it was the fraction of total air that has mixed and 
been allowed to react with a stoichiometric amount of fuel.

\section{$\underline{\text { Results and Discussion }}$}

The inlet analysis revealed that the composition was frozen throughout the inlet for the nondissociated air case and nearly frozen for the NO-contaminated case. Because the test gases for these two cases are the same in terms of molecular weight and specific heat ratio, the resulting pressure, temperature and velocity at the inlet exit/combustor entrance are identical for the two simulations. Table 7 lists the conditions used to define the combustor inflow.

Results of the combustor analysis indicated that combustion is enhanced for the Mach 8 simulation in the AHSTF. Figure 11 compares calculated combustor pressure distributions for the NO-contaminated test gas with those for nondissociated air. For each of the three fueling simulations, the pressure rise is slightly greater for the NO-contaminated air. The increased pressure is a consequence of the increased chemical energy yield, or heat release (also indicated in figure 11) with the presence of NO. As explained in reference 2, NO can enhance combustion by providing an additional path for the production of $\mathrm{H}_{2} \mathrm{O}$, through the following reactions:

$$
\begin{array}{r}
\mathrm{H}+\mathrm{NO}+\mathrm{M} \rightarrow \mathrm{HNO}+\mathrm{M} \\
\mathrm{OH}+\mathrm{HNO} \rightarrow \mathrm{NO}+\mathrm{H}_{2} \mathrm{O}
\end{array}
$$

In reference 2, Jachimowski emphasizes that the second reaction will only occur if a sufficient amount of the HNO radical is produced by the first reaction, which is very sensitive to pressure. Judging from the results shown in figure 11, the pressures encountered in a typical combustor at an AHSTF Mach 8 simulation are high enough for the level of NO in the test gas to have a small effect.

Ultimately, the effect of NO on measured thrust performance is needed. The performance parameter measured during engine tests is the change in thrust, $\Delta \mathrm{F}$, from fuel-off to fuel-on conditions. Assuming that neither the flow in the inlet nor the flow over the external surfaces of the engine change with combustion, $\Delta \mathrm{F}$ is the change in axial force on the combustor and nozzle due to fuel addition and combustion:

$$
\Delta \mathrm{F}=\mathrm{F}_{\text {fuel on }}-\mathrm{F}_{\text {zero fuel }}
$$

where $\mathrm{F}$ is the sum of the pressure and skin friction forces in the axial direction on the combustor and nozzle. Analytically, this net force, F, can be calculated by performing a momentum balance on the combustor-nozzle control volume. Assuming uniform flow and perpendicular fuel injection:

$$
\mathrm{F}=\left(\dot{\mathrm{m}}_{\mathrm{a}}+\dot{\mathrm{m}}_{\mathrm{f}}\right) \mathrm{V}_{\mathrm{e}}-\dot{\mathrm{m}}_{\mathrm{a}} \mathrm{V}_{2}+\mathrm{p}_{\mathrm{e}} \mathrm{A}_{\mathrm{e}}-\mathrm{p}_{2} \mathrm{~A}_{2}
$$

To compare performance for different mass captures, the air specific thrust, $\mathrm{F} / \mathrm{m}_{\mathrm{a}}$, was calculated by dividing equation 3 by the mass flow rate of air, $m_{a}$, through the engine. The SCRAM3 code was used to calculate the specific thrust for the zero-fuel case and the three fueled cases. Then, $\Delta\left(\mathrm{F} / \mathrm{m}_{\mathrm{a}}\right)$, the change in specific thrust from fuel-off to fuel-on conditions, was computed for each equivalence ratio and the results are summarized in figure 12. The overall effect of the NO on performance is seen in this figure, in which results using the NO-contaminated air are compared with the results using nondissociated air. The combustion enhancement effect of the NO results in a very small increase in $\Delta\left(\mathrm{F} / \mathrm{m}_{\mathrm{a}}\right)$ ranging from a 4 percent increase at $\varnothing=0.5$ to about a 1 percent increase at $\varnothing=1.5$.

Although the effect of NO on test engine performance at the Mach 8 simulation is small, the analysis was repeated for the Mach 6 and 7 simulations in order to consider the effect of the higher levels of static pressure for these lower Mach number simulations. The same type of analysis described for the Mach 8 simulation was performed at the Mach 6 and 7 simulations, using the NO-contaminated test gas for comparison with nondissociated air. The analysis used the same Mach 8 configuration, with the same inlet, combustor and nozzle geometry. The Mach 6 simulation was conducted only at $\varnothing=0.5$ and the Mach 7 case at $\varnothing=1.0$. Due to both the lower temperatures and the overall lower NO levels, results calculated for the Mach 6 and 7 simulations indicate virtually no combustion or thrust enhancement.

\section{Concluding Remarks}

The level of nitrogen oxide $\left(\mathrm{NO}_{\mathrm{X}}\right)$ contamination in the NASA Langley Arc-Heated Scramjet Test Facility was quantified analytically over a range of facility operating conditions corresponding to Mach 6, 7 , and 8 flight simulations. Modeling the flow one dimensionally, a finite rate kinetics code was used to compute the $\mathrm{NO}_{\mathrm{X}}$ concentration up to the facility nozzle exit. The results showed that the $\mathrm{NO}_{\mathrm{X}}$ is primarily composed of nitric oxide (NO), and the calculated NO levels were in general agreement with experimental measurements, with both indicating NO levels between 1.0 and 3.2 mole percent for the flight simulation range considered. 
The effect of this nitric oxide contamination on hydrogen/air combustion in a scramjet engine flow path was investigated analytically using a three-temperature combustor code with finite rate chemistry. The study revealed that, for the Mach 8 simulation, for which the calculated NO levels were the highest (approximately 3 mole percent), NO slightly enhances combustion, resulting in a small increase in one-dimensionally calculated thrust performance. The increase in thrust performance ranged from 4 to 1 percent for total fuel equivalence ratios ranging from 0.5 to 1.5 , respectively. At the Mach 6 and 7 simulations, where the temperatures and NO levels were lower, the NO had no effect on calculated thrust performance.

\section{$\underline{\text { References }}$}

1. MacDermott, W. N.; Horn, D. D.; and Fisher, C. J.: Flow Contamination and Flow Quality in Arc Heaters Used For Hypersonic Testing. AIAA-924028, Jul. 1992.

2. Jachimowski, Casimir, J.: An Analysis of Combustion Studies in Shock Expansion Tunnels and Reflected Shock Tunnels. NASA TP-3224, 1992.

3. Morgan, R.G.; Bakos, R. J.; Tamagno, J.; Stalker, R. J.; and Erdos, J. I.: Scramjet Testing - Ground Facility Comparisons. Paper No. ISABE 91194(L), 1991.

4. Guy, Robert W.; Torrence, Marvin G.; Sabol, Alexander P.; and Mueller, James N.: Operating Characteristics of the Langley Mach 7 Scramjet Test Facility. NASA TM-81929, 1981.

5. Thomas, Scott, R.; and Guy, Robert W.: Expanded Operational Capabilities of the Langley Mach 7 Scramjet Test Facility. NASA TP-2186, 1983.

6. McLain, Allen G.; and Rao, C. S. R.: A Hybrid Computer Program for Rapidly Solving Flowing or Static Chemical Kinetic Problems Involving Many Species. NASA TM X-3403, 1976.

7. Howard, R. P.; Dietz, K. L.; McGregor, W. K.; and Limbaugh, C. C.: Nonintrusive Nitric Oxide Density Measurements in the NASA Langley ArcHeated Scramjet Test Facility. AEDC TR-90-29, 1991.
8. Northam, G. Burton.; and Anderson, G. Y.: Supersonic Combustion Ramjet Research at Langley. AIAA -86-0159, Jan. 1986.

Table 1. AHSTF Standard Operating Conditions

\begin{tabular}{|l|c|c|c|}
\hline \multirow{2}{*}{} & \multicolumn{3}{|c|}{ Flight Mach } \\
& Mumber Simulation \\
\cline { 2 - 4 } & Mach 6 & Mach 7 & Mach 8 \\
\hline Parc (MW) & 9.40 & 9.40 & 9.40 \\
\hline $\begin{array}{l}\text { main air } \\
(\mathrm{kg} / \mathrm{s})\end{array}$ & 0.72 & 0.72 & 0.72 \\
\hline $\begin{array}{l}\text { bypass air } \\
(\mathrm{kg} / \mathrm{s})\end{array}$ & 2.19 & 1.32 & 0.71 \\
\hline $\begin{array}{l}\mathrm{p}_{\mathrm{t}, 1} \\
(\mathrm{~atm})\end{array}$ & 35.1 & 28.6 & 23.0 \\
\hline $\begin{array}{l}\mathrm{h}_{\mathrm{t}, \infty} \\
(\mathrm{kJ} / \mathrm{kg})\end{array}$ & 1837 & 2570 & 3552 \\
\hline $\begin{array}{l}\mathrm{T}_{\mathrm{t}, \infty} \\
(\mathrm{K})\end{array}$ & 1660 & 2220 & 2780 \\
\hline
\end{tabular}

Table 2. AHSTF Average Component Heat Losses as a Percentage of Arc Power

\begin{tabular}{|l|c|}
\hline \multicolumn{1}{|c|}{ Component } & Heat Loss, \% \\
\hline Upstream electrode & 10.8 \\
\hline Downstream electrode & 36.0 \\
\hline Plenum injector rings & 0.8 \\
\hline Plenum liner & 3.4 \\
\hline Nozzle throat & 3.0 \\
\hline
\end{tabular}

Table 3. Dissociated Air Reaction Mechanism

\begin{tabular}{|c|c|c|r|}
\hline Reaction & A & n & E \\
\hline $\mathrm{N}+\mathrm{O}_{2} \rightarrow \mathrm{NO}+\mathrm{O}$ & $6.40 \mathrm{E}+09$ & 1.0 & 6300 \\
\hline $\mathrm{N}+\mathrm{NO} \rightarrow \mathrm{N}_{2}+\mathrm{O}$ & $1.60 \mathrm{E}+13$ & 0 & 0 \\
\hline $\mathrm{M}+\mathrm{NO}_{2} \rightarrow \mathrm{NO}+\mathrm{O}$ & $1.16 \mathrm{E}+16$ & 0 & 66000 \\
\hline $\mathrm{O}+\mathrm{NO}_{2} \rightarrow \mathrm{NO}+\mathrm{O}_{2}$ & $1.00 \mathrm{E}+13$ & 0 & 600 \\
\hline $\mathrm{N}+\mathrm{N} \rightarrow \mathrm{N}_{2}+\mathrm{M}$ & $2.80 \mathrm{E}+17$ & -0.8 & 0 \\
\hline $\mathrm{O}+\mathrm{O} \rightarrow \mathrm{O}_{2}+\mathrm{M}$ & $1.10 \mathrm{E}+17$ & -1.0 & 0 \\
\hline
\end{tabular}

Forward reaction rate constants are of the form $k_{f}=A T^{n} \exp (-E / R T)$. Units are in seconds, moles, cubic centimeters, calories and degrees Kelvin. 
Table 4. Heater Exit Conditions and Test Gas Composition

\begin{tabular}{|c|c|c|c|}
\hline \multirow{2}{*}{} & \multicolumn{3}{|c|}{$\begin{array}{c}\text { Flight Mach Number } \\
\text { Simulation }\end{array}$} \\
\cline { 2 - 4 } & Mach 6 & Mach 7 & Mach 8 \\
\hline $\mathrm{p}(\mathrm{atm})$ & 35.1 & 28.6 & 23.0 \\
\hline $\mathrm{T}(\mathrm{K})$ & 4427 & 4395 & 4316 \\
\hline $\begin{array}{c}\text { Mole } \\
\text { Fractions }\end{array}$ & \multicolumn{3}{|}{} \\
\hline $\mathrm{N}_{2}$ & 0.6797 & 0.6788 & 0.6806 \\
\hline $\mathrm{O}_{2}$ & 0.0772 & 0.0751 & 0.0770 \\
\hline $\mathrm{N}$ & 0.0010 & 0.0010 & 0.0009 \\
\hline $\mathrm{O}$ & 0.1472 & 0.1530 & 0.1518 \\
\hline $\mathrm{NO}$ & 0.0862 & 0.0834 & 0.0810 \\
\hline $\mathrm{NO}{ }_{2}$ & 0.0001 & 0.0001 & 0.0001 \\
\hline $\mathrm{Ar}$ & 0.0086 & 0.0086 & 0.0086 \\
\hline
\end{tabular}

Table 5. Plenum and Nozzle Exit Conditions and Test Gas Composition

\begin{tabular}{|c|c|c|c|c|c|c|}
\hline & \multicolumn{6}{|c|}{ Flight Mach Number Simulation } \\
\hline & \multicolumn{2}{|c|}{ Mach 6} & \multicolumn{2}{|c|}{ Mach 7} & \multicolumn{2}{|c|}{ Mach 8} \\
\hline & $\begin{array}{c}\text { plenum } \\
\text { exit }\end{array}$ & $\begin{array}{c}\text { nozzle } \\
\text { exit }\end{array}$ & $\begin{array}{c}\text { plenum } \\
\text { exit }\end{array}$ & $\begin{array}{c}\text { nozzle } \\
\text { exit }\end{array}$ & $\begin{array}{c}\text { plenum } \\
\text { exit }\end{array}$ & $\begin{array}{c}\text { nozzle } \\
\text { exit }\end{array}$ \\
\hline $\mathrm{p}(\mathrm{atm})$ & 35.1 & 0.0187 & 28.6 & 0.0135 & 23.0 & 0.0094 \\
\hline $\mathrm{T}(\mathrm{K})$ & 1614 & 210 & 2144 & 287 & 2783 & 389 \\
\hline \multicolumn{7}{|l|}{$\begin{array}{c}\text { Mole } \\
\text { Fractions }\end{array}$} \\
\hline $\mathrm{N}_{2}$ & 0.7699 & 0.7699 & 0.7702 & 0.7704 & 0.7626 & 0.7659 \\
\hline $\mathrm{O}_{2}$ & 0.1978 & 0.1978 & 0.1983 & 0.1985 & 0.1898 & 0.1940 \\
\hline $\mathrm{O}$ & - & - & 0.0002 & - & 0.0046 & 0.0001 \\
\hline NO & 0.0225 & 0.0224 & 0.0218 & 0.0216 & 0.0336 & 0.0306 \\
\hline $\mathrm{NO}_{2}$ & 0.0005 & 0.0006 & 0.0002 & 0.0002 & 0.0001 & 0.0001 \\
\hline $\mathrm{Ar}$ & 0.0093 & 0.0093 & 0.0093 & 0.0093 & 0.0093 & 0.0093 \\
\hline
\end{tabular}


Table 6. Silane-Hydrogen-Air Mechanism

\begin{tabular}{|c|c|c|c|c|}
\hline & Reaction & $\mathbf{A}$ & $\mathbf{n}$ & $\mathbf{E}$ \\
\hline 1 & $\mathrm{SIH}_{4} \longrightarrow \mathrm{SIH}_{2}+\mathrm{H}_{2}$ & $9.00 \mathrm{E}+12$ & 0 . & 52700 . \\
\hline 2 & $\mathrm{SIH}_{2}+\mathrm{O}_{2} \rightarrow \mathrm{HSIO}+\mathrm{OH}$ & $2.20 \mathrm{E}+14$ & 0 . & 8000. \\
\hline 3 & $\mathrm{SIH}_{2}+\mathrm{H}_{2} \mathrm{O} \rightarrow \mathrm{SIH}_{2} \mathrm{O}+\mathrm{H}_{2}$ & $3.00 \mathrm{E}+12$ & 0. & 11400. \\
\hline 4 & $\mathrm{SIH}_{4}+\mathrm{O}_{2} \longrightarrow \mathrm{SIH}_{3}+\mathrm{HO}_{2}$ & $4.00 \mathrm{E}+13$ & 0 . & 42800 . \\
\hline 5 & $\mathrm{SIH}_{4}+\mathrm{H} \rightarrow \mathrm{SIH}_{3}+\mathrm{H}_{2}$ & $1.50 \mathrm{E}+13$ & 0. & 2500. \\
\hline 6 & $\mathrm{SIH}_{4}+\mathrm{O} \longrightarrow \mathrm{SIH}_{3}+\mathrm{OH}$ & $4.20 \mathrm{E}+12$ & 0. & 1600. \\
\hline 7 & $\mathrm{SIH}_{4}+\mathrm{OH} \longrightarrow \mathrm{SIH}_{3}+\mathrm{H}_{2} \mathrm{O}$ & $8.40 \mathrm{E}+12$ & 0. & 100. \\
\hline 8 & $\mathrm{SIH}_{4}+\mathrm{HO}_{2} \rightarrow \mathrm{SIH}_{3}+\mathrm{H}_{2} \mathrm{O}_{2}$ & $2.00 \mathrm{E}+12$ & 0. & 10000. \\
\hline 9 & $\mathrm{SIH}_{3}+\mathrm{O}_{2} \rightarrow \mathrm{SIH}_{3} \mathrm{O}_{2}$ & $2.00 \mathrm{E}+15$ & 0. & 1200. \\
\hline 10 & $\mathrm{SIH}_{3} \mathrm{O}_{2} \rightarrow \mathrm{SIH}_{2} \mathrm{O}+\mathrm{OH}$ & $3.00 \mathrm{E}+12$ & 0. & 4000. \\
\hline 11 & $\mathrm{HO}_{2}+\mathrm{SIH}_{3} \mathrm{O}_{2} \longrightarrow \mathrm{SIH}_{3} \mathrm{O}_{2} \mathrm{H}+\mathrm{O}_{2}$ & $4.00 \mathrm{E}+10$ & 0. & 0.000 \\
\hline 12 & $\mathrm{H}+\mathrm{SIH}_{3} \mathrm{O}_{2} \mathrm{H} \rightarrow \mathrm{SIH}_{3} \mathrm{O}_{2}+\mathrm{H}_{2}$ & $4.80 \mathrm{E}+13$ & 0. & 7950. \\
\hline 13 & $\mathrm{SIH}_{3}+\mathrm{O}_{2} \longrightarrow \mathrm{SIH}_{3} \mathrm{O}+\mathrm{O}$ & $3.00 \mathrm{E}+12$ & 0. & 0.000 \\
\hline 14 & $\mathrm{SIH}_{3} \mathrm{O}+\mathrm{O}_{2} \rightarrow \mathrm{SIH}_{2} \mathrm{O}+\mathrm{HO}_{2}$ & $2.00 \mathrm{E}+12$ & 0. & 0.000 \\
\hline 15 & $\mathrm{H}+\mathrm{SIH}_{3} \longrightarrow \mathrm{SIH}_{2}+\mathrm{H}_{2}$ & $2.00 \mathrm{E}+13$ & 0. & 0.000 \\
\hline 16 & $\mathrm{O}+\mathrm{SIH}_{3} \rightarrow \mathrm{SIH}_{2} \mathrm{O}+\mathrm{H}$ & $2.00 \mathrm{E}+13$ & 0. & 0.000 \\
\hline 17 & $\mathrm{OH}+\mathrm{SIH}_{3} \longrightarrow \mathrm{SIH}_{2} \mathrm{O}+\mathrm{H}_{2}$ & $6.00 \mathrm{E}+12$ & 0 . & 0.000 \\
\hline 18 & $\mathrm{HO}_{2}+\mathrm{SIH}_{3} \rightarrow \mathrm{SIH}_{2}+\mathrm{H}_{2} \mathrm{O}_{2}$ & $3.00 \mathrm{E}+12$ & 0. & 0.000 \\
\hline 19 & $\mathrm{SIH}_{3}+\mathrm{SIH}_{3} \longrightarrow \mathrm{SIH}_{2}+\mathrm{SIH}_{4}$ & $2.00 \mathrm{E}+12$ & 0. & 0.000 \\
\hline 20 & $\mathrm{SIH}_{2} \mathrm{O}+\mathrm{O}_{2} \rightarrow \mathrm{HSIO}+\mathrm{HO}_{2}$ & $4.00 \mathrm{E}+14$ & 0. & 35000. \\
\hline 21 & $\mathrm{M}+\mathrm{SIH}_{2} \mathrm{O} \longrightarrow \mathrm{HSIO}+\mathrm{H}$ & $2.00 \mathrm{E}+15$ & 0 . & 84500. \\
\hline 22 & $\mathrm{H}+\mathrm{SIH}_{2} \mathrm{O} \rightarrow \mathrm{HSIO}+\mathrm{H}_{2}$ & $3.30 \mathrm{E}+14$ & 0. & 10500. \\
\hline 23 & $\mathrm{O}+\mathrm{SIH}_{2} \mathrm{O} \longrightarrow \mathrm{HSIO}+\mathrm{OH}$ & $1.80 \mathrm{E}+13$ & 0. & 3080. \\
\hline 24 & $\mathrm{OH}+\mathrm{SIH}_{2} \mathrm{O} \rightarrow \mathrm{HSIO}+\mathrm{H}_{2} \mathrm{O}$ & $7.50 \mathrm{E}+12$ & 0. & 170. \\
\hline 25 & $\mathrm{HO}_{2}+\mathrm{SIH}_{2} \mathrm{O} \longrightarrow \mathrm{HSIO}+\mathrm{H}_{2} \mathrm{O}_{2}$ & $1.00 \mathrm{E}+12$ & 0 . & 12000 . \\
\hline 26 & $\mathrm{M}+\mathrm{HSIO} \rightarrow \mathrm{H}+\mathrm{SIO}$ & $5.00 \mathrm{E}+14$ & 0. & 29000. \\
\hline 27 & $\mathrm{HSIO}+\mathrm{O}_{2} \rightarrow \mathrm{SIO}+\mathrm{HO}_{2}$ & $3.00 \mathrm{E}+13$ & 0. & 0.000 \\
\hline 28 & $\mathrm{H}+\mathrm{HSIO} \longrightarrow \mathrm{SIO}+\mathrm{H}_{2}$ & $2.00 \mathrm{E}+14$ & 0 . & 0.000 \\
\hline 29 & $\mathrm{O}+\mathrm{HSIO} \longrightarrow \mathrm{SIO}+\mathrm{OH}$ & $1.00 \mathrm{E}+14$ & 0. & 0.000 \\
\hline 30 & $\mathrm{OH}+\mathrm{HSIO} \longrightarrow \mathrm{SIO}+\mathrm{H}_{2} \mathrm{O}$ & $1.00 \mathrm{E}+14$ & 0. & 0.000 \\
\hline 31 & $\mathrm{HO}_{2}+\mathrm{HSIO} \longrightarrow \mathrm{SIO}+\mathrm{H}_{2} \mathrm{O}_{2}$ & $1.00 \mathrm{E}+14$ & 0. & 0.000 \\
\hline 32 & $\mathrm{OH}+\mathrm{SIO} \longrightarrow \mathrm{SIO}_{2}+\mathrm{H}$ & $4.00 \mathrm{E}+12$ & 0. & 5700. \\
\hline 33 & $\mathrm{HO}_{2}+\mathrm{SIO} \longrightarrow \mathrm{SIO}_{2}+\mathrm{OH}$ & $1.00 \mathrm{E}+12$ & 0. & 0.000 \\
\hline 34 & $\mathrm{O}+\mathrm{SIO} \longrightarrow \mathrm{SIO}_{2}+\mathrm{M}$ & $2.50 \mathrm{E}+15$ & 0. & 4370. \\
\hline 35 & $\mathrm{SIO}+\mathrm{O}_{2} \rightarrow \mathrm{SIO}_{2}+\mathrm{O}$ & $4.00 \mathrm{E}+13$ & 0 . & 6500. \\
\hline
\end{tabular}

Forward reaction rate constants are of the form $k_{f}=A T^{n} \exp (-E / R T)$. Units are in seconds, moles, cubic centimeters, calories and degrees Kelvin. Third body efficiencies for all third body reactions are 2.5 for $\mathrm{M}=\mathrm{H}_{2}, 16.0$ for $\mathrm{M}=\mathrm{H}_{2} \mathrm{O}$, and 1.0 for all other species. 
Table 7. Combustor Inflow Conditions for a Mach 8 Flight Simulation

\begin{tabular}{|c|c|c|}
\hline & Nondissociated air & NO-contaminated air \\
\hline $\mathrm{p}(\mathrm{atm})$ & 0.476 & 0.476 \\
\hline $\mathrm{T}(\mathrm{K})$ & 1112 & 1112 \\
\hline $\mathrm{V}(\mathrm{m} / \mathrm{s})$ & 2012 & 2012 \\
\hline Mole Fractions & \multicolumn{2}{|c|}{} \\
\hline $\mathrm{N}_{2}$ & 0.7812 & 0.7659 \\
\hline $\mathrm{O}_{2}$ & 0.2095 & 0.1941 \\
\hline $\mathrm{Ar}$ & 0.0093 & 0.0093 \\
\hline $\mathrm{NO}$ & - & 0.0306 \\
\hline $\mathrm{NO}_{2}$ & - & 0.0001 \\
\hline
\end{tabular}

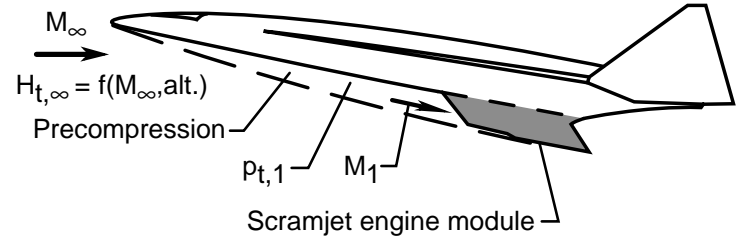

(a) Hypersonic vehicle in flight.

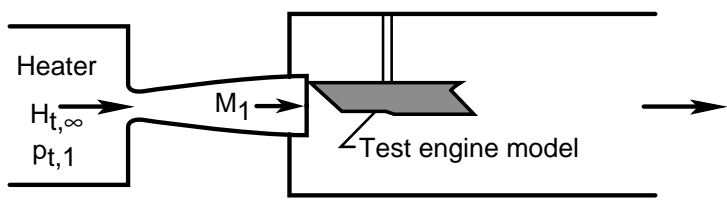

(b) Simulation in ground facility.

Figure 1.- Simulation of flight conditions during scramjet engine testing.

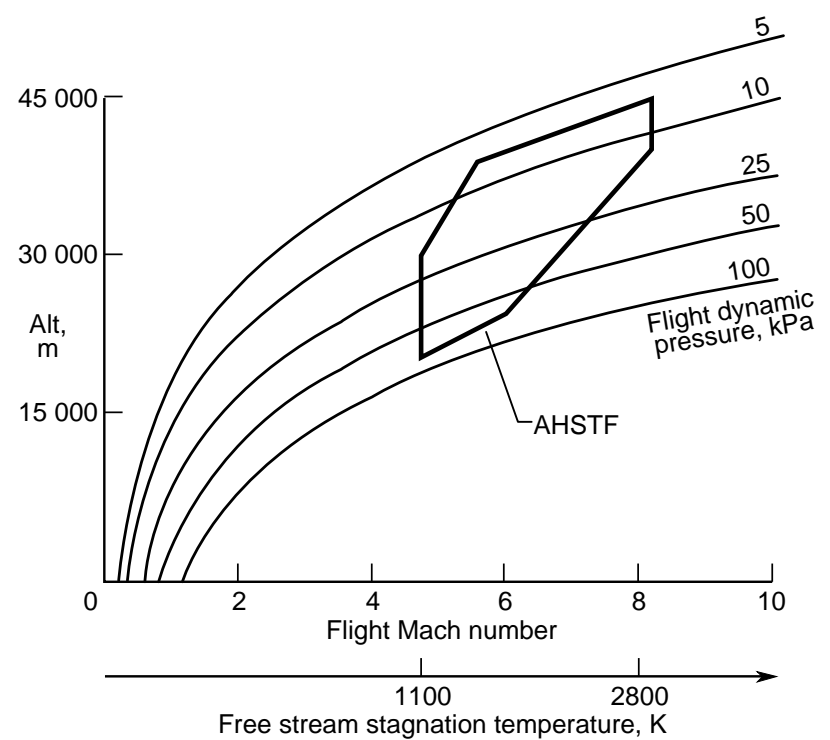

Figure 2.- AHSTF test capability.

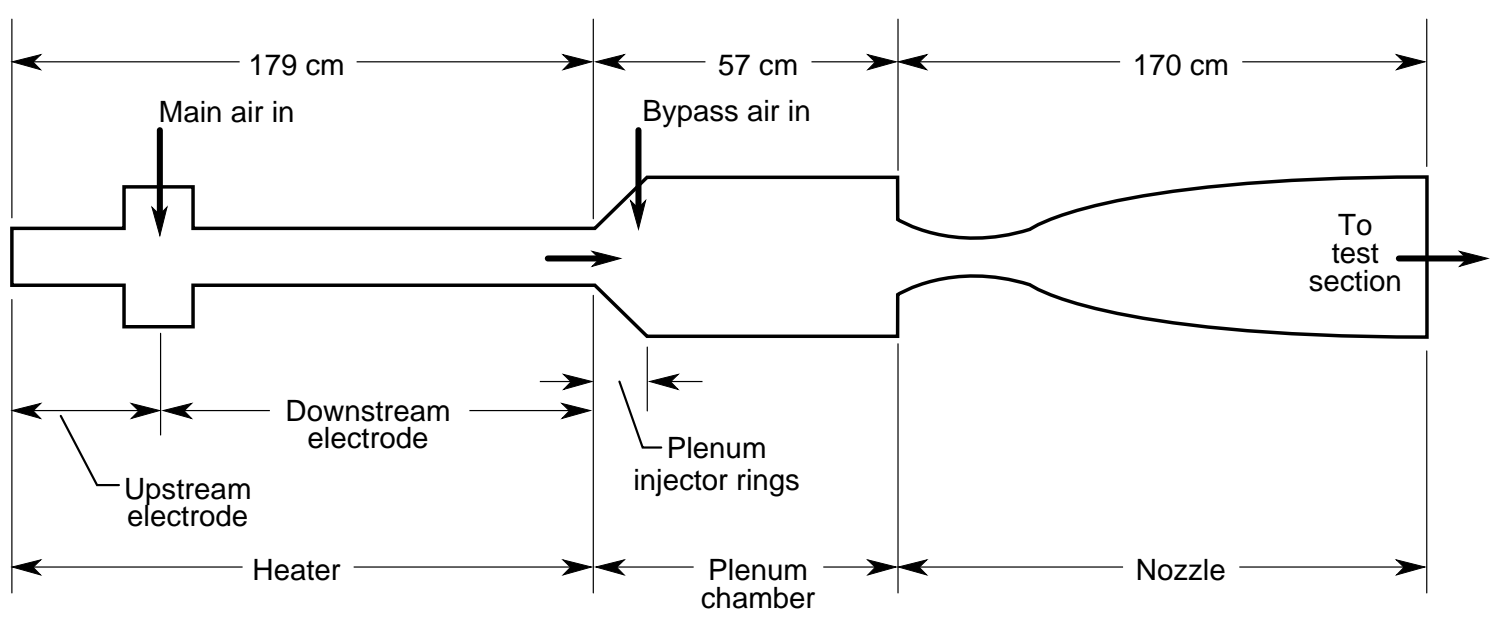

Figure 3.- Schematic of facility arc heater, plenum chamber and nozzle. 


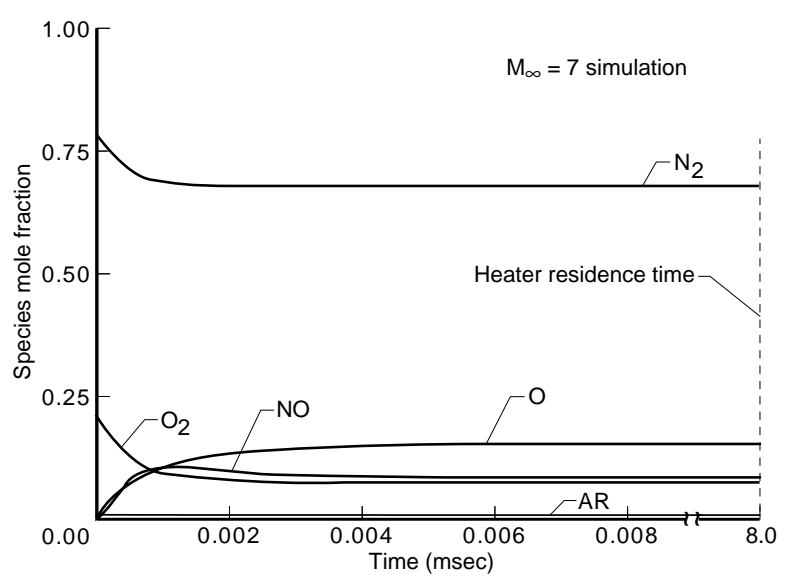

Figure 4.- Air dissociation in arc-heater.

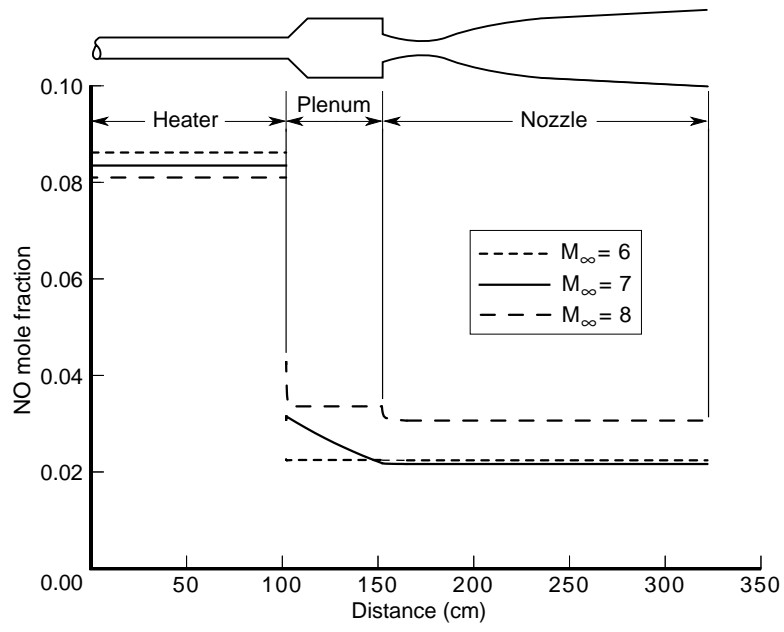

Figure 5.- Calculated NO levels in the facility heater, plenum chamber, and nozzle.

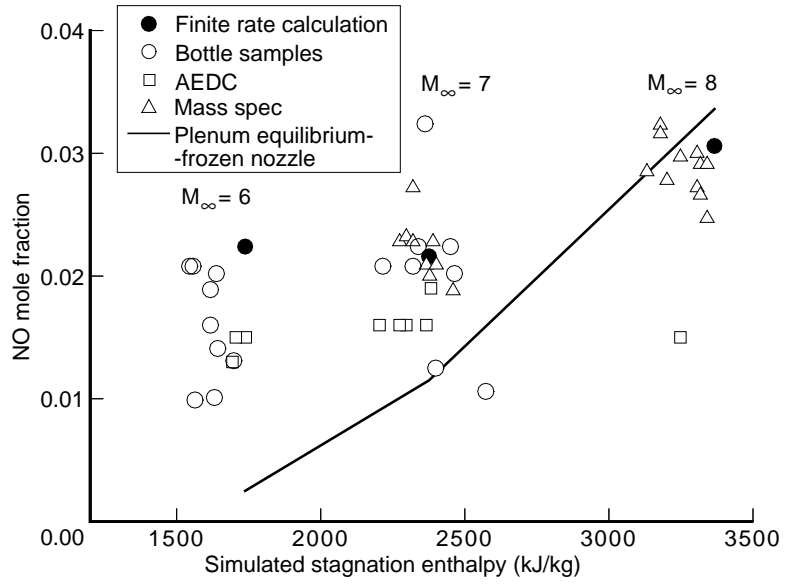

Figure 6.- Calculated and experimental NO levels entering facility test section.

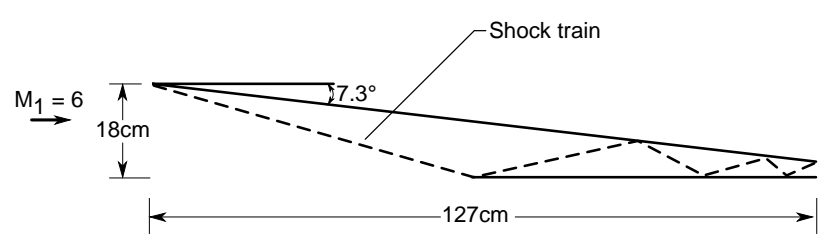

Figure 7.- Inlet model geometry.

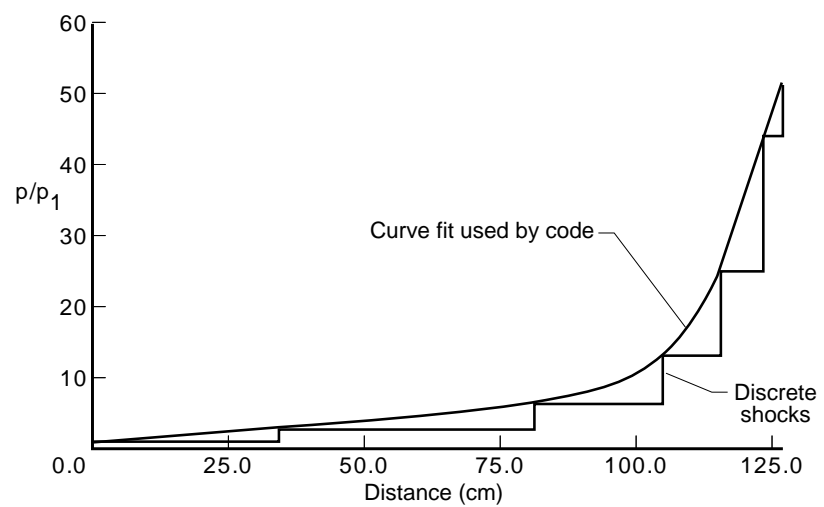

Figure 8.- Pressure distribution for inlet core streamline.

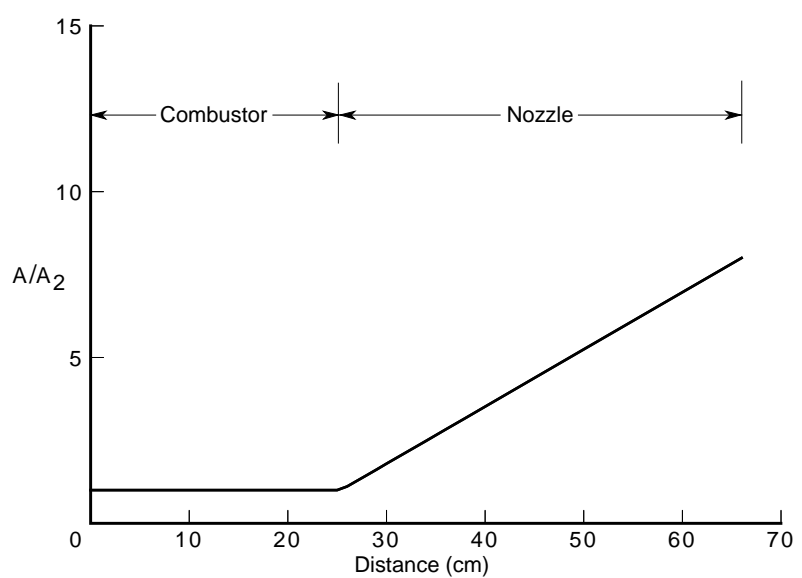

Figure 9.- Combustor-nozzle area distribution. 


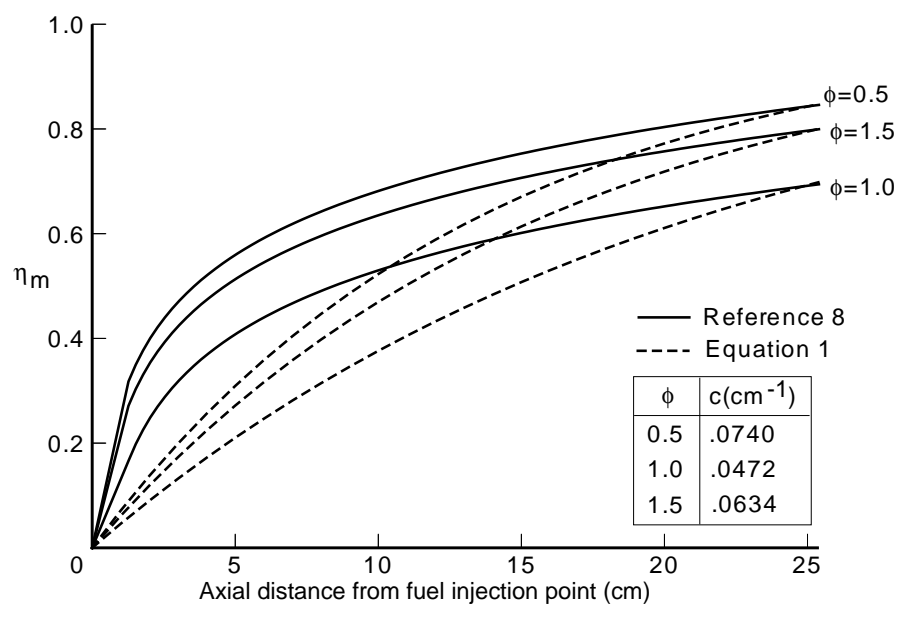

Figure 10.- Combustor fuel-air mixing schedules.

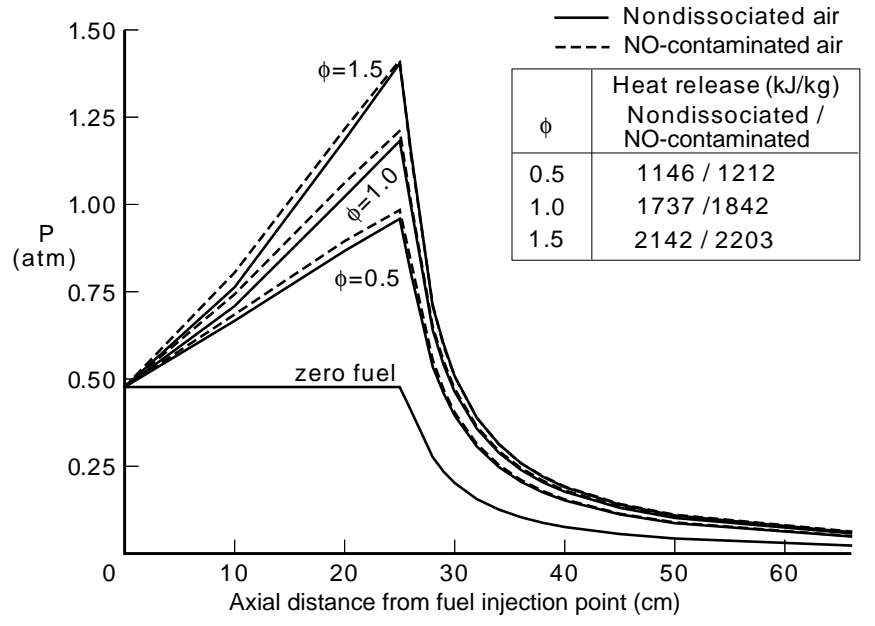

Figure 11.- Calculated combustor pressure distributions at a Mach 8 flight simulation. 


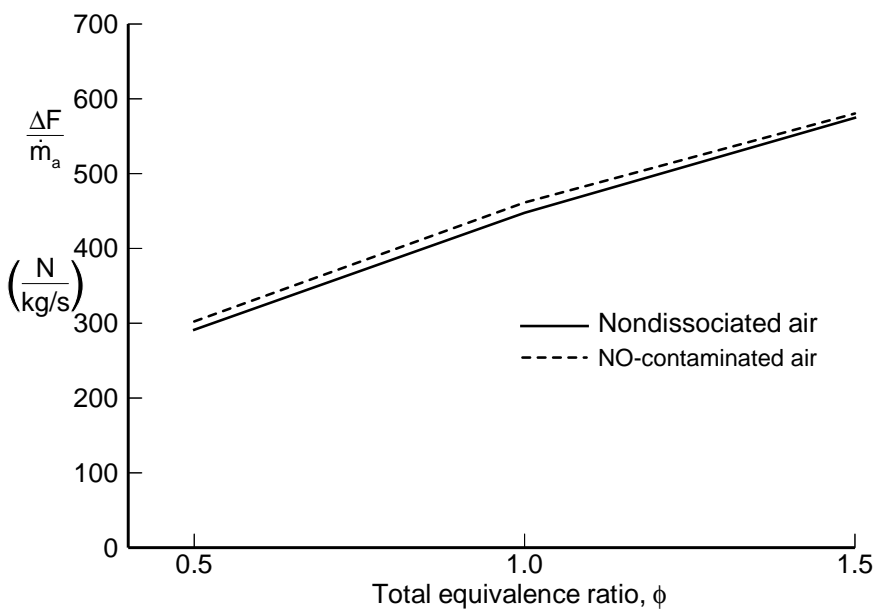

Figure 12.- Calculated effect of NO on thrust performance at a Mach 8 flight simulation. 